CLINICAL STUDY

\title{
GLP1 analogs as treatment of postprandial hypoglycemia following gastric bypass surgery: a potential new indication?
}

\author{
Niclas Abrahamsson ${ }^{1}$, Britt Edén Engström ${ }^{1}$, Magnus Sundbom ${ }^{2}$ and F Anders Karlsson ${ }^{1}$ \\ Departments of ${ }^{1}$ Medical Sciences, University Hospital and ${ }^{2}$ Surgical Sciences, Uppsala University, Uppsala S-751 85, Sweden \\ (Correspondence should be addressed to F A Karlsson; Email: anders.karlsson@medsci.uu.se)
}

\begin{abstract}
Objective: The number of morbidly obese subjects submitted to bariatric surgery is rising worldwide. In a fraction of patients undergoing gastric bypass (GBP), episodes with late postprandial hypoglycemia (PPHG) develop 1-3 years after surgery. The pathogenesis of this phenomenon is not fully understood; meal-induced rapid and exaggerated increases of circulating incretins and insulin appear to be at least partially responsible. Current treatments include low-carbohydrate diets, inhibition of glucose intestinal uptake, reduction of insulin secretion with calcium channel blockers, somatostatin analogs, or diazoxide, a $\mathrm{K}_{\mathrm{ATP}}$ channel opener. Even partial pancreatectomy has been advocated. In type 2 diabetes, GLP1 analogs have a well-documented effect of stabilizing glucose levels without causing hypoglycemia.

Design: We explored GLP1 analogs as open treatment in five consecutive GBP cases seeking medical attention because of late postprandial hypoglycemic symptoms.

Results: Glucose measured in connection with the episodes in four of the cases had been 2.7, 2.5, 1.8, and $1.6 \mathrm{mmol} / \mathrm{l}$ respectively. The patients consistently described that the analogs eliminated their symptoms, which relapsed in four of the five patients when treatment was reduced/discontinued. The drug effect was further documented in one case by repeated 24-h continuous glucose measurements. Conclusion: These open, uncontrolled observations suggest that GLP1 analogs might provide a new treatment option in patients with problems of late PPHG.
\end{abstract}

European Journal of Endocrinology 169 885-889

\section{Introduction}

Obesity is a global and increasing health problem, where medical and diet treatment is often not effective enough. The number of performed bariatric operations is on the rise, with gastric bypass surgery (GBP) being the most common (1).

GBP creates a passage of nutrients through a minute gastric remnant directly into the small intestine. This alteration in anatomy gives rise to side effects: early dumping symptoms and in some cases later discomfort due to postprandial hypoglycemia (PPHG) (2). The dumping syndrome is characterized as an attack within 10-30 min after eating with symptoms of dizziness, diaphoresis, flushing, nausea, bloating, and fatigue. It is believed to be caused by osmotic fluid shifts from blood to lumen, with symptoms also stemming from an activation of the sympathetic system (3). The late reactive symptoms, considered to reflect hypersecretion of insulin in relation to the amount of glucose ingested, arrive 1-3 $\mathrm{h}$ after a meal and include weakness, sweating, dizziness, and fainting, which are the symptoms of neuroglycopenia that ultimately can lead to seizures. These symptoms are known to occur after both partial and total gastrectomy, procedures very similar to GBP.
In a recent study on 1153 patients who had undergone gastrectomy for gastric cancer, $2 / 3$ had had early dumping symptoms and $1 / 3$ experienced late dumping (4). Marsk et al. (5) used the Swedish National Patient Register to extract an absolute risk of $0.2 \%$ for a GBP patient to present with symptoms requiring hospitalization $(0.04 \%$ in the general population). The relative risk of hospitalization due to hypoglycemic symptoms was increased 2.7-fold. The risk was not increased after other types of bariatric surgery.

The mechanism for development of late PPHG is believed to reflect hypersecretion of GIP and GLP1, which are proposed to induce a $\beta$-cell expansion, via increased expression of islet cell transcription factor pancreatic and duodenal homebox-1 protein (PDX1) (2, 6, 7). Service et al. (8) considered nesidioblastosis (here used regarding adult $\beta$-cell hyperplasia) as the pathological basis and performed partial pancreatectomy. In another report, partial pancreatectomy seemed to cure three patients, whereas reversing the GBP in one of these cases did not (9). $\beta$-cell hyperplasia has been questioned by Meier et al. (10), who studied pancreatic tissues from six patients and compared with tissues obtained from 31 obese and 16 lean controls. No 
morphological findings of $\beta$-cell hyperplasia were found but a correlation between $\beta$-cell nucleus diameter (considered a surrogate marker of $\beta$-cell secretory activity) and preoperative BMI was observed.

GBP patients with neuroglycopenic symptoms do not have higher morning values but higher insulin and incretin levels after a mixed meal compared with GBP patients without symptoms (11). When 36 unselected patients at least 6 months postoperative from GBP were examined by $100 \mathrm{~g}$ oral glucose liquid load, 69\% showed glucose values $<3.3 \mathrm{mmol} / \mathrm{l}$ at $120 \mathrm{~min}$, suggestive of reactive hypoglycemia (12). A case report in which food was administered in the empty gastric remnant via gastrostomy abolished gastrointestinal discomfort (13), emphasizing the importance of an intact pyloric function and duodenal passage to avoid dumping and excessive gut hormonal responses.

In patients with type 2 diabetes, GLP1 analogs have a well-documented effect of stabilizing glucose levels without causing hypoglycemia (14). We therefore have tried it as off-label treatment for PPHG following Rouxen-Y GBP. Here, we present five consecutive cases treated with GLP1 analogs at our clinic. Basic characteristics of the patients are given in Table 1. Patients 1, 2, 3, and 5 had not previously presented with diabetes or abnormal glucose tolerance test, used any glucose-modifying medication, or had any other identifiable cause of hypoglycemia. Patient 4 had preoperatively type 2 diabetes and was treated with metformin and glimepirid. The treatment was discontinued shortly after operation. All patients had had frequent meetings with the clinic's specialist dieticians to optimize their eating regimen prior to medication. Patients were given advice to take frequent meals $6-7$ times a day with low carbohydrate and high protein content, to not drink during meals but rather in between, and to keep a food diary.

\section{Patient cases}

\section{Case 1}

This is the index case that made us aware of the possible potential of GLP1 analogs as treatment of PPHG. It was a 44-year-old woman who had a GBP in 2008. She lost a total of $40 \mathrm{~kg}$ and her BMI dropped from 42 to $29 \mathrm{~kg} / \mathrm{m}^{2}$. In May 2011, she was put on GLP1 analog liraglutide as an attempt to boost weight reduction. On an out-clinic visit 3 months later, the patient expressed satisfaction with a weight reduction of $5 \mathrm{~kg}$, but most of all over the fact that her PPHG symptoms had completely disappeared. This troubled her about once per week. During a 1-month withdrawal, the patient experienced relapsing symptoms of hypoglycemia. Presently, the patient is on liraglutide $1.8 \mathrm{mg} /$ day and reports no PPHG at all. The episodes were only reported by the patient, and there are no documented glucose values. The patient was not willing to perform 24-h glucose curves.

\section{Case 2}

This patient is a 33-year-old woman who works as a nurse. She had a preoperative weight of $131 \mathrm{~kg}$ and a BMI of 46. GBP was performed in April 2010, and subsequently the patient's weight reduced to $76 \mathrm{~kg}$ (BMI 27). The patient first complained of PPHG in June 2011. As a nurse, she had access to capillary plasma glucose measuring and could, on repeated occasions, document levels as low as $2.7 \mathrm{mmol} / \mathrm{l}$ a couple of hours after meals. She experienced dizziness, fatigue, heart flutter, and sweating several times a week. Symptoms regressed and glucose values increased upon intake of food with high sugar content. She was initially treated with acarbose and nifedipin, with almost no effect. She was therefore put on liraglutide in September 2011. This had a marked effect and since then she has only had one hypoglycemia episode that came after a meal with 'quite a lot of alcohol' (patient's own words). She is currently treated with liraglutide $1.2 \mathrm{mg} /$ day. In an attempt to lower the dose to $0.6 \mathrm{mg} /$ day, the patient experienced relapse of PPHG.

\section{Case 3}

A 36-year-old woman with a preoperative BMI of 47 had a GBP in 2009. She first complained of PPHG in the summer of 2011, having reached a BMI of 35 . She was examined with continuous glucose monitoring (CGMS)

Table 1 Patient characteristics. Five female GBP patients with late postprandial hypoglycemias defined by typical symptoms experienced 1-3 $\mathrm{h}$ after meal intake.

\begin{tabular}{|c|c|c|c|c|c|c|c|c|c|}
\hline Patient & Age & $\begin{array}{c}\text { Admitted } \\
\text { years after } \\
\text { GBP }\end{array}$ & $\begin{array}{c}\text { BMI }\left(\mathrm{kg} / \mathrm{m}^{2}\right) \\
\text { preop/ } \\
\text { admittance }\end{array}$ & $\begin{array}{l}\text { Baseline } \\
\text { fasting } \\
\text { glucose } \\
\text { (mmol/l) }\end{array}$ & $\begin{array}{c}\text { Baseline } \\
\text { fasting } \\
\text { insulin } \\
(\mathrm{mU} / \mathrm{l})\end{array}$ & $\begin{array}{c}\text { Baseline } \\
\text { HbA1c \% } \\
(\mathrm{mmol} / \mathrm{mol})\end{array}$ & $\begin{array}{c}\text { Lowest } \\
\text { P-glucose } \\
(\mathrm{mmol} / \mathrm{l}) \\
\text { determined } \\
\text { with symptoms }\end{array}$ & $\begin{array}{l}\text { Frequency } \\
\text { of PPHG }\end{array}$ & $\begin{array}{l}\text { Relapse of } \\
\text { symptoms } \\
\text { when lowered } \\
\text { dose or off } \\
\text { drug }\end{array}$ \\
\hline 1 & 44 & 3 & $42 / 29$ & 5.2 & ND & $5.5(37)$ & ND & Weekly & Yes \\
\hline 2 & 33 & 1 & $46 / 27$ & 5.1 & ND & 5.1 (32) & 2.7 & Eod & Yes \\
\hline 3 & 36 & 2 & $47 / 35$ & 5.4 & ND & $5.4(36)$ & 2.5 & Daily & No \\
\hline 4 & 64 & 1 & $51 / 32$ & 4.6 & 1.26 & $6.2(44)$ & 1.8 & Daily & Yes \\
\hline 5 & 45 & 3 & $38 / 27$ & 4.8 & 1.86 & $5.3(34)$ & 1.6 & Weekly & Yes \\
\hline
\end{tabular}

Eod, every other day; ND, not determined. 
for 5 days (Fig. 1a), and repeatedly and several times daily her glucose fell below $3.0 \mathrm{mmol} / \mathrm{l}$, and to 2.5 $\mathrm{mmol} / \mathrm{l}$ at the lowest, $1-2 \mathrm{~h}$ postprandially with symptoms of dizziness and weakness. Symptoms and glucose normalized when eating food with high sugar content. She experienced hypoglycemic problems daily and was given liraglutide $1.2 \mathrm{mg} /$ day in October 2011 as first treatment and responded promptly. Medication was discontinued after 1 year in the fall of 2012 and so far the previous problem with PPHG has not returned. She reports a less stressful life with more time to plan correct and frequent meals.

\section{Case 4}

This 64-year-old woman had her GBP in the spring of 2008. Her preoperative weight of $130 \mathrm{~kg}$ had been reduced to $82 \mathrm{~kg}$ the following year, when she first noted symptoms of hypoglycemia $1-2 \mathrm{~h}$ after meals, predominantly tremor, sweating, and heart flutters. She was given a blood glucose-measuring device and could, on repeated occasions, measure glucose below $2 \mathrm{mmol} / \mathrm{l}$, with a lowest value of $1.8 \mathrm{mmol} / \mathrm{l}$. On CGMS examination for 3 days, the lowest postprandial glucose level was $2.7 \mathrm{mmol} / \mathrm{l}$ (Fig. 1b). The symptoms appeared about once weekly and glucose levels were normalized after eating food with high sugar content. This patient had type 2 diabetes mellitus prior to the operation. When postprandial hypoglycemic episodes appeared, the patient underwent a 3-day fast without hypoglycemias and a CT scan of the abdomen with normal result. She was treated with nifedipin, diazoxide, and acarbose without any effect. In May 2011, she was prescribed liraglutide $1.2 \mathrm{mg}$, and all hypoglycemic episodes immediately disappeared. As this patient experienced heart flutters and diarrhea, medication was changed to exenatide twice daily, later weekly. She then experienced nausea and stomach pains, but still no hypoglycemia. On the basis of side effects, medication was discontinued in October 2012 on the patient's demand. She presently tries to regulate her blood glucose levels with an extremely strict diet; however, the frequent late PPHGs have returned.

\section{Case 5}

A 45-year-old woman with a preoperative weight of $100 \mathrm{~kg}$ and a BMI of 38 had a GBP performed in September 2009. In the spring of 2012, the patient was admitted to the neurological ward because of seizures and unconsciousness, in retrospect most likely due to PPHG, but not diagnosed. The patient was discharged without specific treatment. After that, problems with traditional hypoglycemic symptoms ensued 2-4 h postprandially. The problems, occurring one to two times weekly, regressed when eating food with high sugar content. On examination with CGMS in March 2012, glucose decreased to a minimum of $1.6 \mathrm{mmol} / \mathrm{l}$ postprandially (Fig. 1c). Liraglutide $1.2 \mathrm{mg} /$ day was prescribed as first treatment; subsequently, the patient had very few problems with hypoglycemia. In retrospect, this patient feels invigorated and less slow in thought after medication. When trying to increase the dose to $1.8 \mathrm{mg} /$ day to completely
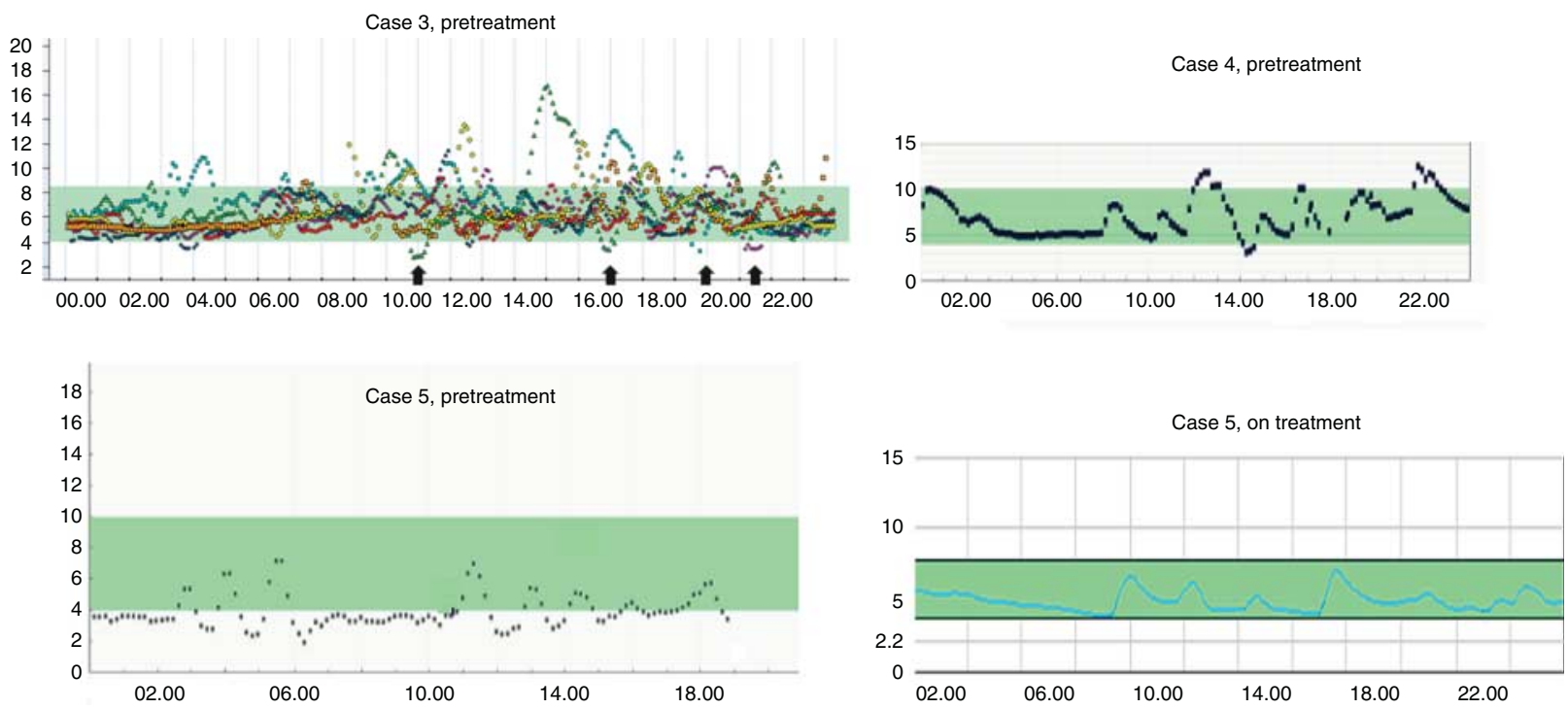

Figure 124 -h continuous glucose measurements (CGMS) in three of the five patients. $Y$-axes represent glucose (mmol/l), $X$-axes represent hour of day. (a; upper left) Case 3; CGMS ('Seven Plus') pretreatment. Postprandial hypoglycemia (PPHG) about $2 \mathrm{~h}$ after breakfast, lunch, and dinner respectively, at different days, indicated by arrows. Each day is represented by an individual symbol. (b; upper right) Case 4; CGMS ('Navigator') pretreatment. PPHG at $1400 \mathrm{~h} 2 \mathrm{~h}$ after lunch meal. (c; lower left) Case 5, CGMS ('Navigator') pretreatment. Several late PPHGs can be seen. (d; lower right) Case 5, CGMS ('Navigator') under treatment, no hypoglycemias can be seen. Full colour version of this figure available via http://dx.doi.org/10.1530/EJE-13-0504. 
stop the hypoglycemia, the patient experiences side effects including nausea and headache. In August 2012, the therapy was therefore changed to weekly exenatide, minimizing side effects without the return of hypoglycemic episodes. A follow-up of the 3-day CGMS showed no hypoglycemia (Fig. 1d).

\section{Discussion}

In this open study, we observed a protective effect of GLP1 analogs on pronounced symptoms of postprandial hypoglycemic episodes in five patients who 1-4 years previously had had GBP surgery at our center.

PPHG in GBP patients seems to have a complex pathogenesis. The normal counter-regulation against low blood glucose is not functioning properly, because of a lack of inhibition to insulin secretion, or subnormal response from the anti-insulinary hormones, or possibly a combination. A key component, however, is the rapid transit and appearance of nutrients in the intestine, causing very marked glucose and insulin elevations as well as increased GLP1 peaks. At meal tests, GBP patients typically show peaks in glucose $30-45 \mathrm{~min}$ postprandially followed by drops down to below baseline at $180 \mathrm{~min}$, while insulin peaks at $30-60 \mathrm{~min}$ and is back to basal levels at 90-120 min $(15,16)$. GLP1 peaks at 15-30 min, falling to basal levels 60-90 min later. The GBP patients also have a stimulated glucagon release, which is not fully understood, and might reflect enteroglucagon released from the intestine, as well as glucagon released from $\alpha$-cells, via stimulation by glucagon-like peptide-2 (17). There are receptors for GLP1 on $\alpha$-cells and on insulin-producing $\beta$-cells and somatostatin-producing $\delta$-cells (18). The number of GLP1 receptors does not seem to be increased in islets from surgical pancreatic tissue specimens (19). The GBP procedure also induces, in addition to several changes in key glucoregulatory hormones, changes in neuronal/ sympathetic activity, the latter less well documented but is reflected for instance in marked changes in vasodilation 1 month after surgery (20).

Nauck et al. (21) showed in 1993 that, in type 2 diabetes patients on GLP1 treatment, glucagon levels in the normo/hypoglycemic state were elevated compared with controls. Ahrén et al. (22) further showed in 2009 that by increasing levels of GLP1, with the DPPIV-inhibitor vildagliptin, the glucagon response to acute hypoglycemia was significantly increased compared with controls. Furthermore, indirect findings indicated that GLP1 receptor activation may make $\beta$-cells more capable of suppressing insulin secretion at low glucose. Possibly, the positive effects of GLP1 analogs in GBP patients with hypoglycemic episodes involve the same glucose-stabilizing mechanism as in patients with diabetes receiving GLP1 active drugs, i.e., in low glucose conditions, a downregulation of the insulin secretion and upregulation of the glucagon level.
When performing a test meal and simultaneously giving i.v. GLP1, male volunteers who received GLP1 showed significantly lower insulin and glucose but higher glucagon postprandially compared with controls (23). Conceivably, the basis for long-acting GLP1 analogs having a positive effect on counteracting late PPHG might be that the endogenous GLP1 has a short window of activity, whereas exogenous GLP1 analogs promote persistent GLP1 receptor activation.

Glucagon has been tried but not proven useful in a GBP case with PPHG (24). Glucagon was given as a continuous infusion during a 4-h period, which included a test meal. At cessation of the glucagon administration, the patient experienced hypoglycemic symptoms. The glucagon infusion was accompanied by high pharmacological levels of glucagon and hyperglycemia and a prolonged hyperinsulinemia, considered to explain why the protocol failed (24). As mentioned, glucagon levels increase in GBP patients following meal intake. In a study by Goldfine et al. (11), no difference in glucagon area under the curve was observed when patients with and without late hypoglycemia were examined with a meal test (which provided $256 \mathrm{kcal}$, $8 \%$ protein, $30 \%$ fat, and $62 \%$ carbohydrate) over $120 \mathrm{~min}$. No symptomatic hypoglycemia was provoked by the tests, however, which would have allowed for an evaluation of counter-regulation. Possibly, patients prone to have late PPHG have insufficient counterregulatory responses and/or low glycogen stores, and these areas deserve future study.

Based on our open observations, we suggest that GLP1 analogs could be tried in severe cases of PPHG, in particular before partial pancreatectomy is discussed. In our view, they are also superior in effect to the currently used treatments, and furthermore, side effects of currently used drugs, i.e. gastrointestinal problems with glucosidase inhibitors, unwanted hormonal side effects, and bile stone formation with somatostatin analogs, hypotension with calcium blockers, and hypertrichosis with diazoxide, can be avoided using GLP1 analogs. When considering this, a prospective, randomized trial to further define the role of GLP1 analogs in treating symptoms of PPHG in GBP patients seems warranted.

\section{Declaration of interest}

The authors declare that there is no conflict of interest that could be perceived as prejudicing the impartiality of the research reported.

\section{Funding}

This research did not receive any specific grant from any funding agency in the public, commercial or not-for-profit sector.

\section{Acknowledgements}

The authors are grateful to the nursing staff of our clinical unit for valuable assistance with glucose measurements and patient care. 


\section{References}

1 Buchwald H, Avidor Y, Braunwald E, Jensen MD, Pories W, Fahrbach K \& Schoelles K. Bariatric surgery: a systematic review and meta-analysis. Journal of the American Medical Association 2004292 1724-1737. (doi:10.1001/jama.292.14.1724)

2 Cui Y, Elahi D \& Andersen DK. Advances in the etiology and management of hyperinsulinemic hypoglycemia after Rouxen-Y gastric bypass. Journal of Gastrointestinal Surgery 201115 1879-1888. (doi:10.1007/s11605-011-1585-8)

3 Hammer HF. Medical complications of bariatric surgery: focus on malabsorption and dumping syndrome. Digestive Diseases 2012 30 182-186. (doi:10.1159/000336681)

4 Mine S, Sano T, Tsutsumi K, Murakami Y, Ehara K, Saka M, Hara K, Fukagawa T, Udagawa H \& Katai H. Large-scale investigation into dumping syndrome after gastrectomy for gastric cancer. Journal of the American College of Surgeons $2010 \mathbf{2 1 1}$ 628-636. (doi:10.1016/j.jamcollsurg.2010.07.003)

5 Marsk R, Jonas E, Rasmussen F \& Näslund E. Nationwide cohort study of post-gastric bypass hypoglycaemia including 5,040 patients undergoing surgery for obesity in 1986-2006 in Sweden. Diabetologia 201053 2307-2311. (doi:10.1007/s00125-0101798-5)

6 Rabiee A, Magruder JT, Salas-Carrillo R, Carlson O, Egan JM, Askin FB, Elahi D \& Andersen DK. Hyperinsulinemic hypoglycemia after Roux-en-Y gastric bypass: unraveling the roles of gut hormonal and pancreatic endocrine dysfunction. Journal of Surgical Research 2011167 199-205. (doi:10.1016/j.jss.2010. 09.047)

7 Vella A \& Service FJ. Incretin hypersecretion in post-gastric bypass hypoglycemia-primary problem or red herring? Journal of Clinical Endocrinology and Metabolism 200792 4563-4565. (doi:10.1210/jc.2007-2260)

8 Service GJ, Thompson GB, Service FJ, Andrews JC, CollazoClavell ML \& Lloyd RV. Hyperinsulinemic hypoglycemia with nesidioblastosis after gastric-bypass surgery. New England Journal of Medicine 2005353 249-254. (doi:10.1056/NEJMoa043690)

9 Patti ME, McMahon G, Mun EC, Bitton A, Holst JJ, Goldsmith J, Hanto DW, Callery M, Arky R, Nose V et al. Severe hypoglycaemia post-gastric bypass requiring partial pancreatectomy: evidence for inappropriate insulin secretion and pancreatic islet hyperplasia. Diabetologia 200548 2236-2240. (doi:10.1007/s00125-0051933-x)

10 Meier JJ, Butler AE, Galasso R \& Butler PC. Hyperinsulinemic hypoglycemia after gastric bypass surgery is not accompanied by islet hyperplasia or increased $\beta$-cell turnover. Diabetes Care 2006 29 1554-1559. (doi:10.2337/dc06-0392)

11 Goldfine AB, Mun EC, Devine E, Bernier R, Baz-Hecht M, Jones DB, Schneider BE, Holst JJ \& Patti ME. Patients with neuroglycopenia after gastric bypass surgery have exaggerated incretin and insulin secretory responses to a mixed meal. Journal of Clinical Endocrinology and Metabolism 200792 4678-4685. (doi:10.1210/jc. 2007-0918)

12 Roslin M, Damani T, Oren J, Andrews R, Yatco E \& Shah P. Abnormal glucose tolerance testing following gastric bypass demonstrates reactive hypoglycemia. Surgical Endoscopy 2011 25 1926-1932. (doi:10.1007/s00464-010-1489-9)
13 McLaughlin T, Peck M, Holst J \& Deacon C. Reversible hyperinsulinemic hypoglycemia after gastric bypass: a consequence of altered nutrient delivery. Journal of Clinical Endocrinology and Metabolism 201095 1851-1855. (doi:10.1210/jc.2009-1628)

14 Montanya E. A comparison of currently available GLP-1 receptor agonists for the treatment of type 2 diabetes. Expert Opinion on Pharmacotherapy 201213 1451-1467. (doi:10.1517/14656566. 2012.692777)

15 Holdstock C, Zethelius B, Sundbom M, Karlsson FA \& Edén Engström B. Postprandial changes in gut regulatory peptides in gastric bypass patients. International Journal of Obesity 200832 1640-1646. (doi:10.1038/ijo.2008.157)

16 Laferrère B, Teixeira J, McGinty J, Tran H, Egger JR, Colarusso A, Kovack B, Bawa B, Koshy N, Lee H et al. Effect of weight loss by gastric bypass surgery versus hypocaloric diet on glucose and incretin levels in patients with type 2 diabetes. Journal of Clinical Endocrinology and Metabolism 200893 2479-2485. (doi:10. 1210/jc.2007-2851)

17 Meier JJ, Nauck MA, Pott A, Heinze K, Goetze O, Bulut K, Schmidt WE, Gallwitz B \& Holst JJ. Glucagon-like peptide 2 stimulates glucagon secretion, enhances lipid absorption, and inhibits gastric acid secretion in humans. Gastroenterology 2006 130 44-54. (doi:10.1053/j.gastro.2005.10.004)

18 Baggio LL \& Drucker DJ. Biology of incretins: GLP-1 and GIP. Gastroenterology 2007132 2131-2157. (doi:10.1053/j.gastro. 2007.03.054)

19 Reubi JC, Perren A, Rehmann R, Waser B, Christ E, Callery M, Goldfine AB \& Patti ME. Glucagon-like peptide-1 (GLP-1) receptors are not overexpressed in pancreatic islets from patients with severe hyperinsulinaemic hypoglycaemia following gastric bypass. Diabetologia 201053 2641-2645. (doi:10.1007/s00125-010-1901-y)

20 Lind L, Zethelius B, Sundbom M, Edén Engström B \& Karlsson FA. Vasoreactivity is rapidly improved in obese subjects after gastric bypass surgery. International Journal of Obesity 200933 1390-1395. (doi:10.1038/ijo.2009.188)

21 Nauck MA, Kleine N, Ørskov C, Holst JJ, Willms B \& Creutzfeldt W. Normalization of fasting hyperglyceamia by exogenous glucagonlike peptide 1 (7-36 amide) in type 2 (non-insulin-dependent) diabetic patients. Diabetologia 199336 741-744. (doi:10.1007/ BF00401145)

22 Ahrén B, Schweizer A, Dejager S, Dunning BE, Nilsson PM, Persson M \& Foley JE. Vildagliptin enhances islet responsiveness to both hyper- and hypoglycemia in patients with type 2 diabetes. Journal of Clinical Endocrinology and Metabolism 200994 1236-1243. (doi:10.1210/jc.2008-2152)

23 Meier JJ, Gethmann A, Götze O, Gallwitz B, Holst JJ, Schmidt WE \& Nauck MA. Glucagon-like peptide 1 abolishes the postprandial rise in triglyceride concentrations and lowers levels of nonesterified fatty acids in humans. Diabetologia $2006 \mathbf{4 9} 452-458$. (doi:10.1007/s00125-005-0126-y)

24 Halperin F, Patti ME \& Goldfine AB. Glucagon treatment for postgastric bypass hypoglycemia. Obesity $2010 \mathbf{1 8} 1858-1860$. (doi:10.1038/oby.2010.15)

Received 20 June 2013

Revised version received 19 August 2013

Accepted 1 October 2013 